\title{
Electrophysical propertis of solid solutions of $\mathrm{Zn}_{2-x}\left(\mathrm{Ti}_{\mathbf{a}} \mathbf{Z r}_{\mathbf{b}}\right)_{1-x} \mathrm{Fe}_{2 x} \mathrm{O}_{4}$
}

\author{
Rudik Hamazaspi Grigoryan ${ }^{1}$, Levoh Hamazaspi Grigoryan ${ }^{2}$ \\ ${ }^{1}$ Institute of Structural Macrokinetics and Materials Science, Russian Academy of Sciences, Moscow, Russia \\ ${ }^{2}$ Institute of Problems of Chemical Physics, Russian Academy of Sciences, Moscow, Russia \\ Academician Semenova av. 1, Chernogolovka, Moscow, Russia \\ Email: rud@ism.ac.ru, hrant31@icp.ac.ru
}

Received 17 July 2012; revised 30 August 2012; accepted 16 September 2012

\begin{abstract}
Electrophysical properties of multicomponent system $\mathrm{Zn}_{2} \mathrm{TiO}_{4}-\mathrm{Zn}_{2} \mathrm{ZrO}_{4}-\mathrm{ZnFe}_{2} \mathbf{O}_{4}$ were investigated. The electrical conductivity, band gap, dielectric permittivity, and molar polarizability of formed solid solutions$\mathrm{Zn}_{2-x}\left(\mathrm{Ti}_{\mathrm{a}} \mathrm{Zr}_{\mathrm{b}}\right)_{1-x} \mathrm{Fe}_{2 x} \mathrm{O}_{4}(x=0$ - 1.0 are defined; $\Delta x=$ $0.05 ; a+b=1 ; a: b=1: 5 ; 1: 4 ; 1: 3 ; 1: 2 ; 1: 1 ; 2: 1 ; 3: 1$; 4:1) were defined. Electrophysical properties of samples are in linear dependence on their composition. All the synthesized samples are semiconductors with high electrical resistivity. Was confirmed the formation of two phases of variable composition with a wide homogeneity range.
\end{abstract}

Keywords: Spinel; Solid Solutions; Electrical Conductivity; Band Gap; Dielectric Permittivity; Polarizability

\section{INTRODUCTION}

Quickly developing electronic industry puts before chemical science problem searching for of the new compounds, possessing valuable electrophysical characteristics and their deepened physic-chemical study. Such are, in particular, hard melting complex oxides. The Special interest present the complex oxides and formed by them hard solutions, containing d-elements, differing broad area of homogeneity, expressed dielectric, semiconductor, superconductive, optical and the other characteristic.

The electrical properties of solid solutions with broad homogeneity ranges vary systematically with composition, which enables the fabrication of materials with tailored properties. There is considerable research interest in refractory mixed transition metal oxides and their solid solutions, which have broad homogeneity ranges and attractive dielectric, semiconducting, superconducting, optical and other properties [1,2]. Divalent metal orthotitanates are widely used in semiconductor technology as bulk resistors and microwave ceramics [2]. $\mathrm{ZnO}$ enriched zinc orthotitanate was proposed as a candidate material for nonlinear and bulk resistors [3].

In a recent $x$-ray diffraction study [4], two phases ( $\alpha$ and $\beta$ ) with broad homogeneity regions were identified in the $\mathrm{Zn}_{2} \mathrm{TiO}_{4}-\mathrm{Zn}_{2} \mathrm{ZrO}_{4}-\mathrm{ZnFe}_{2} \mathrm{O}_{4}$ system at $1170 \mathrm{~K}$. The $\alpha$-phase crystallizes in a cubic structure and the b-phase in a tetragonal inverse spinel structure. Their stability limits and the structural parameters of $\mathrm{Zn}_{2-x}\left(\mathrm{Ti}_{\mathrm{a}} \mathrm{Zr}_{\mathrm{b}}\right)_{1-x} \mathrm{Fe}_{2 x} \mathrm{O}_{4}$ samples were determined, and the cation distribution over the tetrahedral and octahedral interstices in the oxygen sublattice of the spinel structure was assessed. Electrophysical parameters of formed hard solution were not studied earlier.

In this paper, we report the electrical properties of solid solutions in the $\mathrm{Zn}_{2} \mathrm{TiO}_{4}-\mathrm{Zn}_{2} \mathrm{ZrO}_{4}-\mathrm{ZnFe}_{2} \mathrm{O}_{4}$ system.

\section{METHODS OF THE EXPERIMENT}

The Syntheses of $\mathrm{Zn}_{2-x}\left(\mathrm{Ti}_{\mathrm{a}} \mathrm{Zr}_{\mathrm{b}}\right)_{1-x} \mathrm{Fe}_{2 x} \mathrm{O}_{4}$ (where $x=0,0$ $1.0 ; x=0.05 ; \mathrm{a}+\mathrm{b}=1$ ) were realized in two ways - in low temperature plasma of hydrogen-oxygen flame [5] and well-known ceramic technology. As source material were a used especially purec reagents: $\mathrm{ZnO}, \mathrm{TiO}_{2}, \mathrm{Fe}_{2} \mathrm{O}_{3}$ and $\mathrm{ZrO}_{2}$. For the synthesis were prepared by a mixture of $(2-x) \mathrm{ZnO}+\mathrm{a}(1-x) \mathrm{TiO}_{2}+\mathrm{b}(1-x) \mathrm{ZrO}_{2}+x \mathrm{Fe}_{2} \mathrm{O}_{3}$, where $\mathrm{a}: \mathrm{b}=1: 5 ; 1: 4 ; 1: 3 ; 1: 2 ; 1: 1 ; 2: 1 ; 3: 1 ; 4: 1 ; x=0-1.0, x=$ 0.05 . Samples for measurement were prepared by pressing (200 MPa) divided powder (65 microns) synthesis of solid solutions in the form of tablet $(\mathrm{d}=20 \mathrm{~mm}, 1=2$ $\mathrm{mm})$. The tablets were subjected to heat treatment at $1170 \mathrm{~K}$ for $2 \mathrm{~h}$, followed by rapid cooling on a copper substrate. Conductivity of the samples was measured by a standard four-probe potentiometric method, with electrical contacts made by firing silver paste. Temperature dependence of electrical conductivity was measured in the temperature range 293 - $900 \mathrm{~K}$. Dielectric permittivity was measured by the flat condenser method. Molar polarizability was evaluated using the Clauzius-Mossotti equation. Dielectric permittivity measured the method of 
flat condenser.

\section{RESULTS AND DISCUSSION}

It was established the identity of the investigated physical properties of samples of identical compositions synthesized in low-temperature plasma and ceramic technology. The following are data from the study of the samples synthesized at low temperature plasma. All of the synthesized samples are dielectrics with semiconducting behavior of conductivity with specific resistivity fro$\mathrm{m} 10^{7}$ to $10^{12} \mathrm{ohm} \cdot \mathrm{cm}$. Comparison of the results obtained values of electrical parameters and the constructed composition-property diagram confirms biphasic of system $\mathrm{Zn}_{2} \mathrm{TiO}_{4}-\mathrm{Zn}_{2} \mathrm{ZrO}_{4}-\mathrm{ZnFe}_{2} \mathrm{O}_{4}$ and $(1170 \mathrm{~K})$ and the boundaries of homogeneous phases (Table 1) previously established by X-ray diffraction method [5]. In Table 2 shows the values of the density of single-phase samples, certain pycnometric method at room temperature. As can be seen from these data, a significant change in the density of solid solutions in the whole concentration range is observed.

$\boldsymbol{\alpha}$-phase. The results of measurements of electrical parameters of the $\alpha$-phase are shown in Table 2. As can be seen from these data, the electrical properties of solid solutions are most sensitive to iron content.

Changes in the relative content of titanium and zirconium, with a constant iron content does not lead to significant changes in the physical properties (Table 3). For example, a value of $x=0.7$ (1.4 mol of iron content) change in the ratio a:b $1: 5$ to $4: 1$ leads to an increase in conductivity of one order $\left(2.34 \times 10^{-9}\right.$ to $5.01 \times 10^{-8}$ $\left.\mathrm{ohm}^{-1} \cdot \mathrm{cm}^{-1}\right)$. At the same time slightly decreases the band gap (1.31 eV to $1.08 \mathrm{eV}$ ) and the dielectric constant and polarization parameters are changed slightly. While the increase in iron content in the $\alpha$-phase leads to an increase in the specific conductivity of solid solutions of 2 - 3 orders of magnitude, depending on the relative content of titanium and zirconium.

Depending on the electrophysical parameters of the samples from the $\alpha$-phase composition are almost linear for all tested values of a:b. In Figure 1 shows the graphical dependence of the electrical conductivity and dielectric constant of solid solutions of $\alpha$-phase system for cutting $a: b=3: 1$. As can be seen from the data Table 2 , the polarization characteristics of the samples at the same time did not significantly change.

$\boldsymbol{\beta}$-phase. The results of measurements of electrical parameters of samples are given in Table 3. Samples of $\beta$-phases are more low electrical conductivity. As in the case of $\alpha$-phase, increasing iron content leads to a decrease in the band gap and hence to an increase in electrical conductivity of the samples. The lowest conductivity observed in the solid solution containing no iron, and contains the maximum number of zircon $(x=0, \mathrm{a}: \mathrm{b}=1: 5)$.
Table 1. The boundaries of homogeneous phases in the system $\mathrm{Zn}_{2-x}\left(\mathrm{Ti}_{\mathrm{a}} \mathrm{Zr}_{\mathrm{b}}\right)_{1-x} \mathrm{Fe}_{2 x} \mathrm{O}_{4}$.

\begin{tabular}{ccc}
\hline [Ti]:[Zr] & \multicolumn{2}{c}{$x$} \\
\cline { 2 - 3 } & $\alpha$-phase & $\beta$-phase \\
\hline $1: 5$ & 0.70 to 1.0 & 0.0 to 0.47 \\
$1: 4$ & 0.69 to 1.0 & 0.0 to 0.46 \\
$1: 3$ & 0.69 to 1.0 & 0.0 to 0.45 \\
$1: 2$ & 0.66 to 1.0 & 0.0 to 0.40 \\
$1: 1$ & 0.58 to 1.0 & 0.0 to 0.25 \\
$2: 1$ & 0.36 to 1.0 & - \\
$3: 1$ & 0 to 1.0 & - \\
$4: 1$ & 0 to 1,0 & - \\
\hline
\end{tabular}

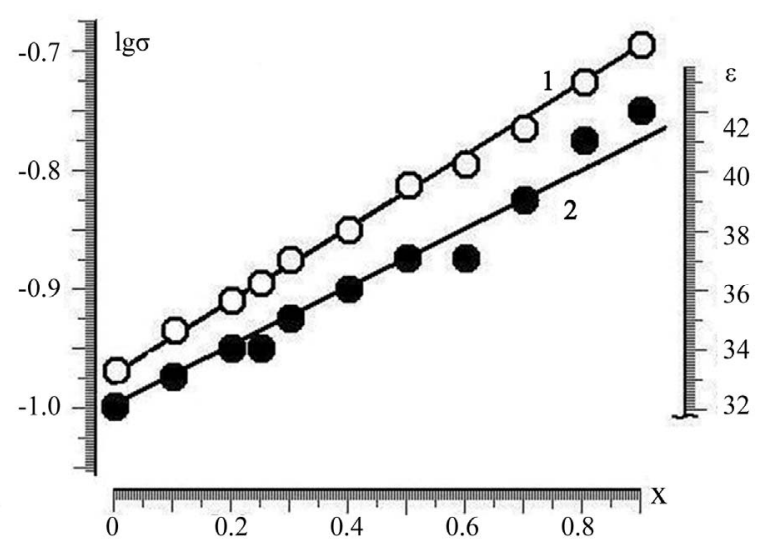

Figure 1. The dependence of the conductivity (1) and the dielectric constant (2) of solid solutions $\alpha$-phase from the composition in the $\mathrm{Zn}_{2-x}\left(\mathrm{Ti}_{\mathrm{a}} \mathrm{Zr}_{\mathrm{b}}\right)_{1-x} \mathrm{Fe}_{2 x} \mathrm{O}_{4}(\mathrm{a}: \mathrm{b}=3: 1)$.

Among the synthesized solid solutions of our best meets these criteria, the sample does not contain iron, with a maximum content of zirconium

$\left(\mathrm{Zn}_{2} \mathrm{Ti}_{0.167} \mathrm{Zr}_{0.833} \mathrm{O}_{4}, \sigma=5.68 \times 10-12 \mathrm{ohm}^{-1} \cdot \mathrm{cm}^{-1}\right)$. In the sample with the highest iron content

$\left(\mathrm{Zn}_{1.55} \mathrm{Ti}_{0.1} \mathrm{Zr}_{0.5} \mathrm{Fe}_{0.9} \mathrm{O}_{4}\right)$, electrical conductivity higher by nearly three orders of magnitude $\left(\sigma=2.51 \times 10^{-9} \mathrm{ohm}^{-1} \cdot \mathrm{cm}^{-1}\right)$.

Depending on the electrophysical parameters of the samples as the $\alpha$ - and $\beta$-phases of the composition are almost linear for all tested sections. In Figure 2 shows the dependence of these cuts for $a: b=1: 3$ and $a: b=1: 5$.

An exponential dependence of the electrical conduction of samples as the $\alpha$ - and $\beta$-phases of the temperature (Figure 3). Raising the temperature from 293 to $900 \mathrm{~K}$ leads to an increase in conductivity up to 4 orders of magnitude. Significant changes in the densities of the samples throughout the concentration range is not observed (Table 4). 
Table 2. Depending on the electrical conductivity $\left(\sigma, \mathrm{ohm}^{-1} \cdot \mathrm{cm}^{-1}\right)$, the band gap $\left(\Delta E^{*}, \mathrm{eV}\right)$, the dielectric permittivity $\left(\varepsilon^{* *}\right)$, molar polarization $\left(P^{* * *}, \mathrm{~cm}^{3}\right)$ of the $\alpha$-phase compositions of $\mathrm{Zn}_{2-x}\left(\mathrm{Ti}_{\mathrm{a}} \mathrm{Zr}_{\mathrm{b}}\right)_{1-x} \mathrm{Fe}_{2 x} \mathrm{O}_{4}$.

\begin{tabular}{|c|c|c|c|c|c|c|c|c|}
\hline$x$ & $\sigma$ & $\Delta E$ & $\varepsilon$ & $P$ & $\sigma$ & $\Delta E$ & $\varepsilon$ & $P$ \\
\hline & & $=1: 5$ & & & \multicolumn{4}{|c|}{$a: b=1: 4$} \\
\hline 0.7 & $2.34 \times 10^{-9}$ & 1.31 & 39 & 42.31 & $2.37 \times 10^{-9}$ & 1.26 & 39 & $42 \times 23$ \\
\hline 0.8 & $2.14 \times 10^{-8}$ & 1.05 & 41 & 42.88 & $3.31 \times 10^{-8}$ & 1.18 & 41 & $42 \times 33$ \\
\hline 0.9 & $2.00 \times 10^{-7}$ & 1.00 & 42 & 42.32 & $2.05 \times 10^{-7}$ & 1.00 & 42 & 42.34 \\
\hline \multicolumn{5}{|c|}{$a: b=1: 3$} & \multicolumn{4}{|c|}{$a: b=1: 2$} \\
\hline 0.7 & $2.37 \times 10^{-9}$ & 1.26 & 39 & 42.23 & $2.69 \times 10^{-9}$ & 1.29 & 36 & 41.90 \\
\hline 0.8 & $3.31 \times 10^{-8}$ & 1.18 & 41 & 42.33 & $2.34 \times 10^{-8}$ & 1.17 & 39 & 42.13 \\
\hline 0.9 & $2.05 \times 10^{-7}$ & 1.00 & 42 & 42.34 & $2.24 \times 10^{-7}$ & 1.04 & 42 & 42.28 \\
\hline \multicolumn{5}{|c|}{$a: b=1: 1$} & \multicolumn{4}{|c|}{$a: b=2: 1$} \\
\hline 0.4 & - & - & - & - & $4.68 \times 10^{-9}$ & 1.14 & 38 & 42.09 \\
\hline 0.5 & - & - & - & - & $6.31 \times 10^{-9}$ & 1.11 & 40 & 42.28 \\
\hline 0.6 & $1.00 \times 10^{-9}$ & 1.08 & 39 & 42.18 & $1.59 \times 10^{-8}$ & 1.08 & 40 & 42.26 \\
\hline 0.7 & $3.39 \times 10^{-9}$ & 1.05 & 40 & 42.28 & $3.39 \times 10^{-8}$ & 1.05 & 42 & 42.39 \\
\hline 0.8 & $2.00 \times 10^{-8}$ & 1.02 & 42 & 42.35 & $6.17 \times 10^{-8}$ & 1.02 & 42 & 42.33 \\
\hline 0.9 & $1.12 \times 10^{-7}$ & 0.99 & 43 & 42.35 & $1.26 \times 10^{-7}$ & 0.99 & 43 & 42.34 \\
\hline \multicolumn{5}{|c|}{$a: b=3: 1$} & \multicolumn{4}{|c|}{$a: b=4: 1$} \\
\hline 0.0 & $2.01 \times 10^{-10}$ & 1.19 & 32 & 42.64 & $1.81 \times 10^{-9}$ & 1.18 & 33 & 43.10 \\
\hline 0.1 & $4.47 \times 10^{-10}$ & 1.17 & 33 & 42.64 & $2.82 \times 10^{-9}$ & 1.16 & 34 & 42.75 \\
\hline 0.2 & $7.94 \times 10^{-10}$ & 1.14 & 34 & 42.61 & $4.47 \times 10^{-9}$ & 1.14 & 34 & 41.08 \\
\hline 0.3 & $1.74 \times 10^{-9}$ & 1.11 & 35 & 42.53 & $7.41 \times 10^{-9}$ & 1.11 & 35 & 42.58 \\
\hline 0.4 & $3.16 \times 10^{-9}$ & 1.09 & 36 & 42.74 & $1.18 \times 10^{-8}$ & 1.09 & 36 & 42.53 \\
\hline 0.5 & $7.08 \times 10^{-9}$ & 1.11 & 37 & 42.74 & $1.51 \times 10^{-8}$ & 1.07 & 37 & 42.50 \\
\hline 0.6 & $1.12 \times 10^{-8}$ & 1.10 & 37 & 42.35 & $3.02 \times 10^{-8}$ & 1.05 & 38 & 42.44 \\
\hline 0.7 & $2.82 \times 10^{-8}$ & 1.08 & 39 & 42.34 & $5.01 \times 10^{-8}$ & 1.02 & 38 & 42.32 \\
\hline 0.8 & $4.47 \times 10^{-8}$ & 1.03 & 41 & 42.47 & $7.94 \times 10^{-8}$ & 1.00 & 40 & 42.36 \\
\hline 0.9 & $1.12 \times 10^{-7}$ & 1.01 & 42 & 42.42 & $1.38 \times 10^{-7}$ & 0.98 & 42 & 42.44 \\
\hline 1.0 & - & - & - & - & $6.61 \times 10^{-7}$ & 0.96 & 43 & 42.73 \\
\hline
\end{tabular}

${ }^{*} \pm 0.02 ;{ }^{* *} \pm 1 ;{ }^{* * *} \pm 0.05$.

Table 3. Depending on the electrical conductivity $\left(\sigma, \mathrm{ohm}^{-1} \cdot \mathrm{cm}^{-1}\right)$. The band gap $\left(\Delta E^{*}, \mathrm{eV}\right)$. the dielectric permittivity $\left(\varepsilon^{* *}\right)$ and molar polarization $\left(P^{* * * *}, \mathrm{~cm}\right)$ of $\beta$-phase compositions of $\mathrm{Zn}_{2-x}\left(\mathrm{Ti}_{\mathrm{a}} \mathrm{Zr}_{\mathrm{b}}\right)_{1-x} \mathrm{Fe}_{2 x} 0_{4}$.

\begin{tabular}{|c|c|c|c|c|c|c|c|c|c|}
\hline$x$ & $\sigma$ & $\Delta E$ & $\varepsilon$ & $P$ & $\sigma$ & $\Delta E$ & $\varepsilon$ & & $P$ \\
\hline & & $a: b=1: 5$ & & & \multicolumn{5}{|c|}{$a: b=1: 4$} \\
\hline 0.0 & $5.68 \times 10^{-12}$ & 1.78 & 25 & 47.62 & $6.30 \times 10^{-12}$ & 1.81 & 25 & & 45.44 \\
\hline 0.1 & $3.16 \times 10^{-11}$ & 1.61 & 28 & 45.79 & $2.51 \times 10^{-11}$ & 1.56 & 28 & & 45.40 \\
\hline 0.2 & $5.24 \times 10^{-11}$ & 1.50 & 31 & 47.22 & $7.94 \times 10^{-11}$ & 1.48 & 31 & & 45.42 \\
\hline 0.25 & $3.16 \times 10^{-10}$ & 1.47 & 32 & 45.02 & $2.18 \times 10^{-10}$ & 1.42 & 33 & & 45.28 \\
\hline 0.3 & $5.01 \times 10^{-10}$ & - & 33 & - & $4.17 \times 10^{-10}$ & 1.41 & 34 & & 45.01 \\
\hline 0.4 & $1.03 \times 10^{-9}$ & 1.42 & 35 & 47.49 & $1.51 \times 10^{-9}$ & 1.41 & 35 & & 44.69 \\
\hline \multirow[t]{2}{*}{0.45} & $2.51 \times 10^{-9}$ & 1.39 & 36 & 47.64 & $3.72 \times 10^{-9}$ & 1.38 & 37 & & 44.60 \\
\hline & & $a: b=1: 3$ & & & \multicolumn{5}{|c|}{$a: b=1: 2$} \\
\hline 0.0 & $1.09 \times 10^{-11}$ & 1.69 & 25 & 44.88 & $1.86 \times 10^{-11}$ & 1.71 & 27 & & 44.92 \\
\hline 0.1 & $3.31 \times 10^{-11}$ & 1.58 & 29 & 45.24 & $5.25 \times 10^{-11}$ & 1.60 & 30 & & 45.13 \\
\hline 0.2 & $1.10 \times 10^{-10}$ & 1.52 & 32 & 45.00 & $1.82 \times 10^{-10}$ & 1.54 & 33 & & 45.21 \\
\hline 0.3 & $3.02 \times 10^{-10}$ & 1.47 & 35 & 45.01 & $4.786 \times 10^{-10}$ & 1.45 & 34 & & 44.70 \\
\hline 0.4 & $1.03 \times 10^{-10}$ & 1.36 & 36 & 44.73 & $1.445 \times 10^{-9}$ & 1.36 & 35 & & 44.57 \\
\hline 0.45 & $1.74 \times 10^{-9}$ & 1.33 & 38 & 44.80 & $2.51 \times 10^{-9}$ & 1.30 & 36 & & 44.61 \\
\hline \multicolumn{10}{|c|}{$a: b=1: 1$} \\
\hline$x$ & $\sigma$ & $\Delta E$ & $\varepsilon$ & $P$ & $x$ & $\sigma$ & $\Delta E$ & $\varepsilon$ & $P$ \\
\hline 0.0 & $4.89 \times 10^{-11}$ & 1.48 & 30 & 44.27 & 0.2 & $3.89 \times 10^{-10}$ & 1.29 & 36 & 44.25 \\
\hline 0.1 & $1.59 \times 10^{-10}$ & 1.39 & 33 & 44.27 & 0.25 & $5.13 \times 10^{-10}$ & 1.23 & 37 & 43.94 \\
\hline
\end{tabular}


Table 4. Densitys $\left(\mathrm{d}_{\text {pickn., }} \mathrm{g} / \mathrm{cm}^{3}\right)$ of solid solutions $\alpha$ - and $\beta$ phases compositions of $\mathrm{Zn}_{2-x}\left(\mathrm{Ti}_{\mathrm{a}} \mathrm{Zr}_{\mathrm{b}}\right)_{1-x} \mathrm{Fe}_{2 x} \mathrm{O}_{4}$.

\begin{tabular}{ccccccccc}
\hline & \multicolumn{7}{c}{$\mathrm{d} \pm 0,01$} \\
\hline & $4: 1$ & $3: 1$ & $2: 1$ & $1: 1$ & $1: 2$ & $1: 3$ & $1: 4$ & $1: 5$ \\
0 & 5.27 & 5.28 & - & 5.34 & 5.34 & 5.34 & 5.36 & 5.36 \\
0.1 & 5.22 & 5.30 & - & 5.32 & 5.32 & 5.32 & 5.30 & 5.29 \\
0.2 & 5.20 & 5.30 & - & - & 5.30 & 5.30 & 5.28 & 5.25 \\
0.25 & 5.16 & 5.29 & - & - & 5,28 & 5.28 & 5.28 & 5.25 \\
0.3 & 5.16 & 5.31 & - & - & 5.29 & 5.29 & 5.28 & 5.27 \\
0.4 & 5.16 & 5.30 & 5.55 & - & 5.26 & 5.26 & 5.22 & 5.24 \\
0.5 & 5.19 & 5.28 & 5.30 & - & - & - & - & - \\
0.6 & 5.18 & 5.27 & 5.24 & 5.36 & - & - & - & - \\
0.7 & 5.15 & 5.25 & 5.55 & 5.30 & 5.52 & 5.52 & 5.42 & - \\
0.8 & 5.12 & 5.24 & 5.30 & 5.26 & 5.33 & 5.33 & 5.33 & - \\
0.9 & - & 5.23 & 5.24 & 5.22 & 5.33 & 5.33 & 5.25 & - \\
\hline
\end{tabular}

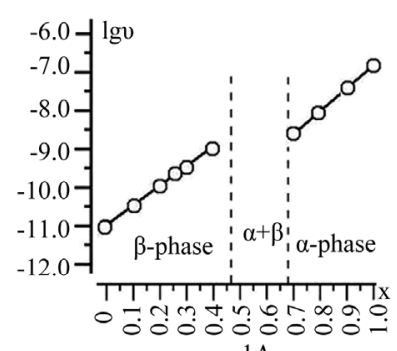

$1 \mathrm{~A}$

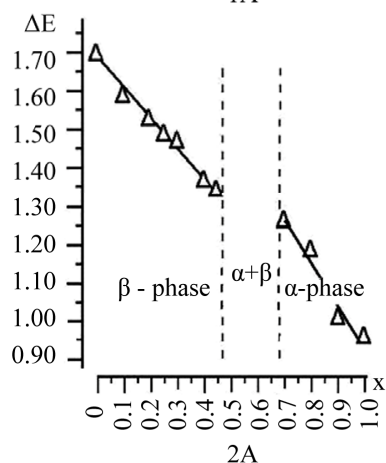

$2 \mathrm{~A}$

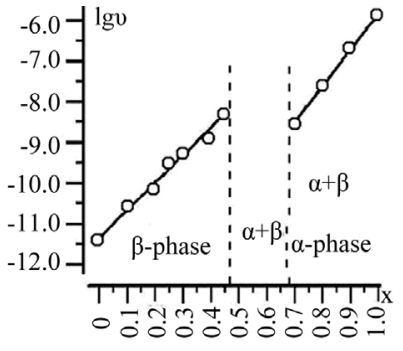

$1 \mathrm{~B}$

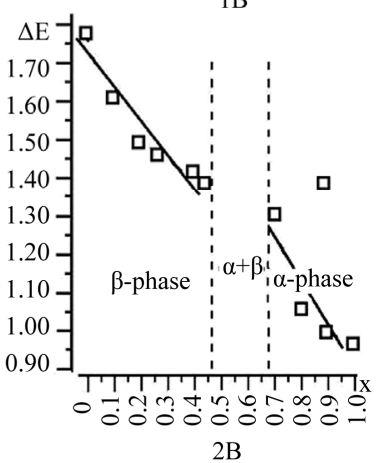

Figure 2. The Dependency to conductivity (1) and width of the forbidden zone (2) of solid solutions $\mathrm{Zn}_{2-x}\left(\mathrm{Ti}_{\mathrm{a}} \mathrm{Zr}_{\mathrm{b}}\right)_{1-x} \mathrm{Fe}_{2 x} \mathrm{O}_{4}$. (A) for $a: b=1: 3$ and $(B)$ for $a: b=1: 5$.

The proportional dependence of the electrical conductivity of samples of the content of $\mathrm{Fe} 3$ and semiconductor conductivity indicate the donor-acceptor mechanism of the electrical conductivity of the samples can be explained to the valence exchange (electron hopping) between the iron ions: $\mathrm{Fe}^{3+} \rightarrow \mathrm{Fe}^{2+}+\mathrm{o}^{+}$and $\mathrm{Fe}^{2+}+\mathrm{o}^{+} \rightarrow$ $\mathrm{Fe}^{3+}$. Other possible similar schemes $\left(\mathrm{Ti}^{4+} \rightarrow \mathrm{Ti}^{3+}+\mathrm{o}^{+}\right.$, or $\left.\mathrm{Zr}^{3+}+\mathrm{o}^{+} \rightarrow \mathrm{Zr}^{4+}\right)$, are unlikely. Increasing the tita-

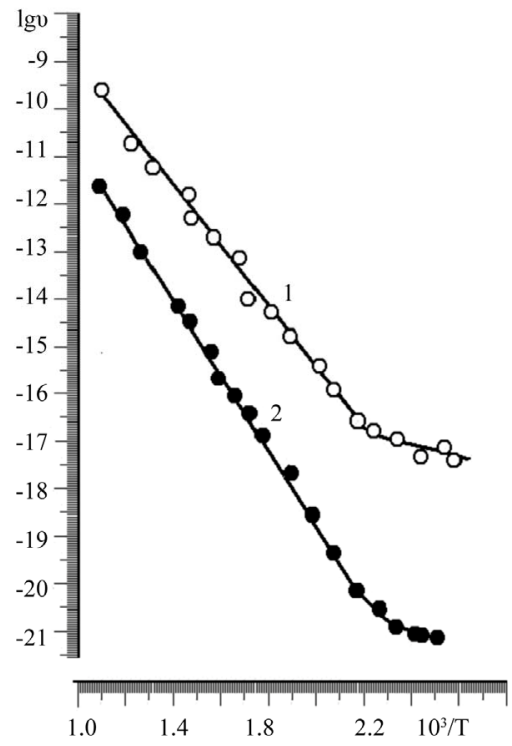

Figure 3. The temperature dependence of conductivity: $\lg \sigma=\mathrm{f}(1 / \mathrm{T})$ of solid solutions $\mathrm{Zn}_{2-x}\left(\mathrm{Ti}_{\mathrm{a}} \mathrm{Zr}_{\mathrm{b}}\right)_{1-x} \mathrm{Fe}_{2 x} \mathrm{O}_{4}$; (1) $\alpha$-phase; $x=0.5$; $\mathrm{a}: \mathrm{b}=3: 1$; (2) $\beta$-phase, $x=0.3$; $\mathrm{a}: \mathrm{b}=4: 1$.

nium and zircon content, accompanied by a decrease in iron content, do not lead to an increase, but on the contrary, a significant reduction in the electrical conductivity of the samples. A similar pattern is also observed when replacing ions $\mathrm{Sn}^{4+}$ by $\mathrm{Fe}^{3+}[6]$.

\section{CONCLUSION}

Were synthesized and investigated the electrical properties of samples of a multicomponent system $\mathrm{Zn}_{2} \mathrm{ZrO}_{4}{ }^{-}$ $\mathrm{Zn}_{2} \mathrm{TiO}_{4}-\mathrm{ZnFe}_{2} \mathrm{O}_{4}$. In the system formed two phases with wide homogeneity ranges. It was established that all the synthesized samples are semiconductors with high electrical resistivity. The values of electrical conductivity, band gap, dielectric constant and molar polarizability of the solid solution compositions $\mathrm{Zn}_{2-x}\left(\mathrm{Ti}_{\mathrm{a}} \mathrm{Zr}_{\mathrm{b}}\right)_{1-x} \mathrm{Fe}_{2 x} \mathrm{O}_{4}$ were determined. All the studed properties vary linearly with the composition of the solid solutions. Increased iron content leads to a significant increase in conductivity of the samples (up to 3 orders of magnitude), simultaneously the width of the band gap and polarizability of the samples decreased.

\section{REFERENCES}

[1] Pasynkov, V.V. and Sorokin, V.S. (1986) Materialy elektronnoi tekhniki (electronic materials). Vysshaya Shkola, Moscow.

[2] Yanagida, H.M. (1986) Tonkaya tekhnicheskaya keramika (fine technical ceramics). Metallurgiya, Moscow.

[3] Loshkarev, B.A. and Semirikov, I.S. (1967) Properties 
and Structure of $\mathrm{ZnO}-\mathrm{TiO}_{2}$ Ceramics. Neorganicheskie. Materiali, 3, 1467-1473.

[4] Grigoryan, R.A. and Grigoryan, L.A. (2004) Synthesis and properties of $\mathrm{Zn}_{2-\mathrm{x}}\left(\mathrm{Ti}_{\mathrm{a}} \mathrm{Zr}_{\mathrm{b}}\right)_{1-\mathrm{x}} \mathrm{Fe}_{2 \mathrm{x}} \mathrm{O}_{4}$ solutions. Neorganicheskie. Materiali, 40, 351-356.

[5] Grigoryan, R.A., Grigoryan, L.A. and Babayan, G.G.
(2001) Synthesis of $\mathrm{ZnFeO}-\mathrm{Zn} \mathrm{ZrO}$ solid solutions. $\mathrm{Ne}$ organicheskie. Materiali, 37, 367-370.

[6] Grigoryan, R.A. and Grigoryan, L.A. (2004) Synthesis and properties of $\mathrm{Zn}_{2} \mathrm{TiO}_{4}-\mathrm{Zn}_{2} \mathrm{SnO}_{4}-\mathrm{ZnFe}_{2} \mathrm{O}_{4}$ solid solutions. Inorganic Materials, 40, 295-299. 